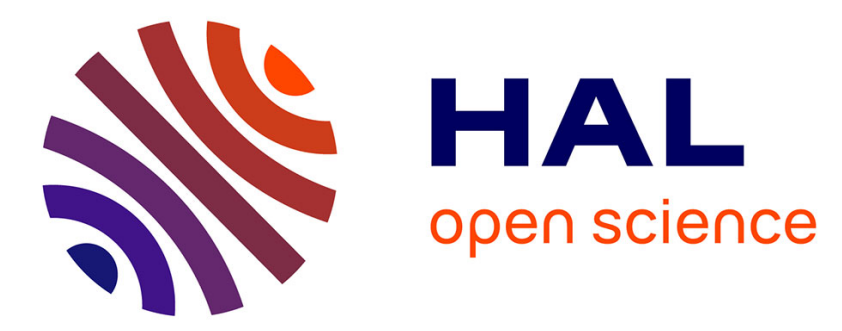

\title{
Levitation of water and organic substances in high static magnetic fields
}

E. Beaugnon, R. Tournier

\section{To cite this version:}

E. Beaugnon, R. Tournier. Levitation of water and organic substances in high static magnetic fields. Journal de Physique III, 1991, 1 (8), pp.1423-1428. 10.1051/jp3:1991199 jpa-00248667

\section{HAL Id: jpa-00248667 https://hal.science/jpa-00248667}

Submitted on 1 Jan 1991

HAL is a multi-disciplinary open access archive for the deposit and dissemination of scientific research documents, whether they are published or not. The documents may come from teaching and research institutions in France or abroad, or from public or private research centers.
L'archive ouverte pluridisciplinaire HAL, est destinée au dépôt et à la diffusion de documents scientifiques de niveau recherche, publiés ou non, émanant des établissements d'enseignement et de recherche français ou étrangers, des laboratoires publics ou privés. 
Classification

Physics Abstracts

$07.55-81.80$

Short Communication

\title{
Levitation of water and organic substances in high static magnetic fields
}

\author{
E. Beaugnon and R. Tournier \\ Centre National de la Recherche Scientifique, Centre de Recherches sur les Très Basses \\ Températures, Laboratoire associé à l'université Joseph Fourier, 25 avenue des Martyrs, 166X - \\ Centre de tri, 38042 Grenoble Cedex, France
}

(Received 12 March 1991, accepted 16 April 1991)

\begin{abstract}
Résumé. - En utilisant les forts champs magnétiques produits par la bobine hybride du Service National des Champs Intenses (CNRS, Grenoble), nous avons obtenu à température ambiante la lévitation de substances diamagnétiques solides ou liquides telles que l'eau, l'alcool, l'acétone, le bismuth, l'antimoine, le graphite, le bois et le plastique. Ces résultats montrent que les bobines supraconductrices peuvent être utilisées pour l'élaboration de nombreux matériaux en gravité réduite, sans contact avec un contenant.

Abstract. - The levitation of various diamagnetic liquid and solid substances such as water, ethanol, acetone, bismuth, antimony, graphite, wood and plastic has been achieved at room temperature in a strong inhomogeneous static magnetic field. These experiments were performed in the hybrid magnet at the Service National des Champs Intenses (CNRS, Grenoble). These findings show that high field superconducting magnets could be used to provide a contactless, low gravity environment for the elaboration of a wide range of materials.
\end{abstract}

\section{Introduction.}

Levitation of bodies is of great interest for contactless elaboration of pure materials and can be achieved by numerous techniques $[1,2]$. One of them is the use of a strong inhomogeneous static magnetic field, but there has been no recent investigation of the ability of high field magnets to levitate organic and mineral solids and liquids. In this paper, we report on experiments showing that even so-called non magnetic materials (which are in fact weakly diamagnetic) may nowadays be levitated in strong magnetic fields.

\section{Magnetic force.}

The magnetic energy per unit volume $W$, of a particle in a magnetic field is :

$$
\dot{W}=\int_{0}^{\mathbf{B}_{\mathrm{a}}} \mathbf{M} \mathrm{dB}, \text { with } \mathbf{B}_{\mathrm{a}}=\mu_{0} \mathbf{H}_{\mathrm{a}},
$$


where $\mathbf{H}_{\mathrm{a}}$ is the applied field, $\mu_{0}$ the permeability of free space, and $M$ the magnetization of the particle. $\mathbf{B}$ is the magnetic induction or magnetic flux density. When a field gradient exists, a magnetic force tends to drive the particle to regions where its energy is lowered.

For the case of paramagnetic and diamagnetic particles, $\mathbf{M}$ is related to $\mathbf{H}$ through a dimensionless constant $K$, the susceptibility $(K>0$ for paramagnetic and $K<0$ for diamagnetic particles). For our purpose, it is helpful to consider the specific susceptibility $\chi$. Then the magnetic force per unit mass, $\mathbf{F}$, is :

$$
\mathbf{F}=\left(\chi / 2 \mu_{0}\right) \operatorname{grad}\left(\mathbf{B}_{\mathrm{a}}^{2}\right) .
$$

In S.I. units, $F$ is in $\mathrm{N} / \mathrm{kg}$, grad $\left(B_{a}^{2}\right)$ in $\mathrm{T}^{2} / \mathrm{m}$ and $\chi$ in $\mathrm{m}^{3} / \mathrm{kg}$. The value of $\mu_{0}$ is $4 \pi \times 10^{-7} \mathrm{H} / \mathrm{m}$. When the vertical force is stronger than gravity, levitation occurs.

In our experiments, we used vertical coils, in which fields have an axial symmetry. We first consider the case of a particle on the axis of the coil where only a vertical component $B_{z}$ of the field exists. Effects of the variations of the field off the axis will be discussed later. In this case, the vertical force $F_{z}$ is :

$$
F_{z}=\left(\chi / \mu_{0}\right) B_{z} \mathrm{~d} B_{z} / \mathrm{d} z
$$

Typical field and force profiles obtained are presented in figure 1.

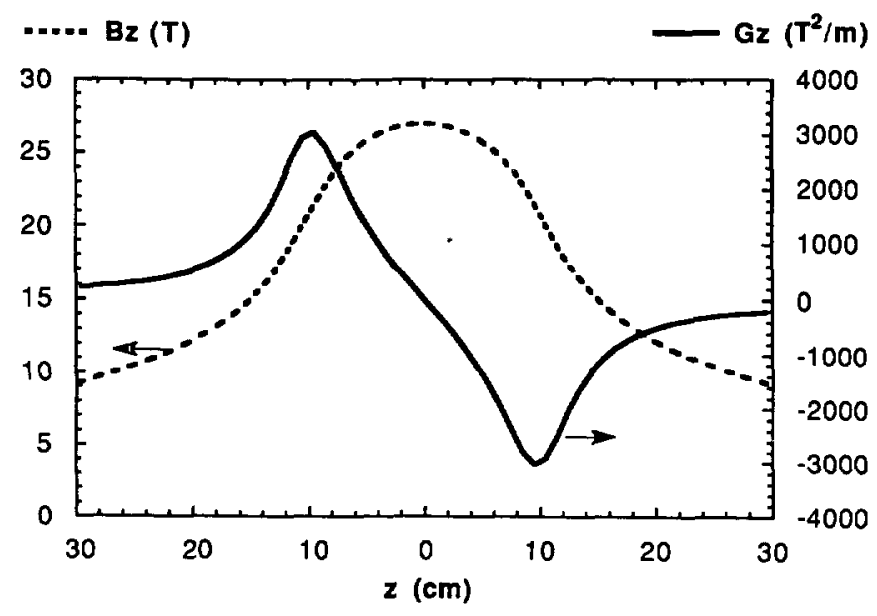

Fig. 1. - Field profiles in the hybrid magnet operating at 27 T. $B_{z}$ is the vertical (and only) component of the field on the axis of the coil. $G_{z}$ is the vertical (and only) component of grad $\left(\mathbf{B}_{\mathrm{a}}^{2} / 2\right)$ on the axis of the coil (i.e. $B_{z} \mathrm{~d} B_{z} / \mathrm{d} z$ ). $z$ is the distance above the center of the coil. To calculate the force acting on a material, one has to multiply $G_{z}$ by $\left(\chi / \mu_{0}\right)$. Levitation may occur for $z<0$ for paramagnetic particles, and for $z>0$ for diamagnetic particles. Vertical stability is obtained when the absolute value of $G_{z}$ decreases with $z$.

Levitation may occur below the centre of the coil for paramagnetic bodies or above for diamagnetic ones, when the maximum force is higher than $9.81 \mathrm{~N} / \mathrm{kg}$. Stability versus the vertical distance above the center of the coil, $z$, is obtained in regions where the force decreases with increasing $z$. 


\section{Experiments.}

We first studied levitation of various diamagnetic liquids and solids : bismuth, antimony, plastic, wood, water, alcohol and acetone. Experiments were performed in the hybrid magnet of the Service National des Champs Intenses, Grenoble, France, with fields up to $27 \mathrm{~T}$. The apparatus are described schematically in figure 2 . Solids were placed in a glass tube fitted with an infra-red barrier. The experimental procedure was as follows:

- the field was raised to a desired value,

- the glass tube containing the sample was lowered inside the magnet bore, until the infrared barrier was below the point of maximum force,

- the field was slowly lowered.

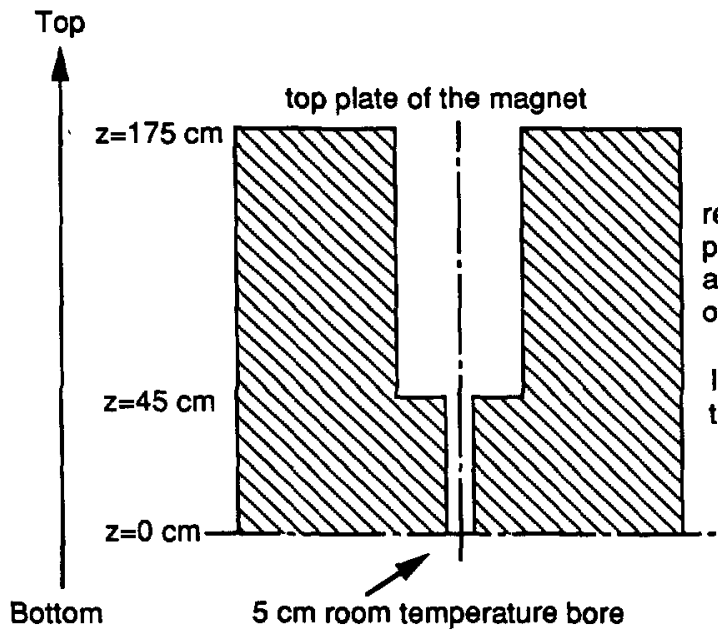

a)

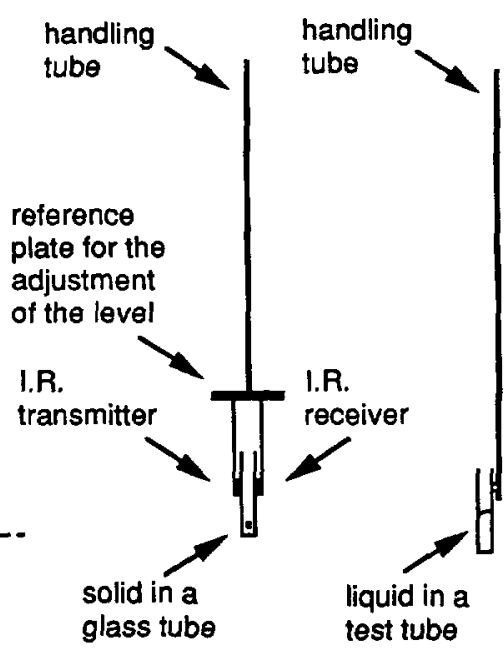

b) c)

Fig. 2. - a) schematic configuration of the hybrid magnet; b) apparatus for levitation of solids ; c) apparatus for levitation of liquids. Levitation of solids is detected by the breaking of an infra-red barrier, levitation of liquids is visually observed and confirmed by verifying the levels of the liquid in the test tube before and after the experiment.

Levitation was detected by the breaking of the infra-red barrier when the glass tube was lowered into the magnet. The minimum field required to obtain levitation was determined by the breaking of the infra-red barrier as the sample fell when the field was lowered.

Liquids were placed in a test tube. Levitation was observed by using two different procedures :

- the field was first raised and levitation may occur when the test tube was lowered into the magnet;

- the test tube was first lowered around the point of maximum force and levitation may occur as the field was raised.

Levitation was observed visually using binoculars and verified by checking the liquid levels in the test tube before and after the experiment, since if levitation occurs, some liquid is lost from the test tube. Results of the experiments are summarized in table I. The deduced susceptibilities of small pure samples of $\mathrm{Bi}$ and $\mathrm{Sb}$ are in good agreement with the literature [3] and confirm the validity of our experiments. Values for other materials are only approximate since shape and size effects and purity have not been taken into account. 
Table I. - Conditions for levitation in the hybrid magnet for the different samples studied. Good agreement between the deduced susceptibilities and the data in [3] for pure samples of Bi and $S b$ confirms the validity of our experiments. $B_{z}$ and $G_{z}$ are as defined in figure 1 . The value of $B_{z}$ is measured at the centre of the coil, the value of $G_{z}$ is calculated at the point of maximum force.

\begin{tabular}{|c|c|c|}
\hline sample & conditions for levitation & remarks \\
\hline $\mathrm{Sb}$ & $\begin{array}{c}\mathrm{Bz}=18.75 \mathrm{~T} \\
\mathrm{Gz}=1208 \mathrm{~T}^{2} / \mathrm{m}\end{array}$ & $\begin{array}{c}\chi \text { calculated : } 1.02110^{-8} \mathrm{~m}^{3} / \mathrm{kg} \\
\chi \text { in }[3]: 1.021810^{-8} \mathrm{~m}^{3} / \mathrm{kg}\end{array}$ \\
\hline $\mathrm{Bi}$ & $\begin{aligned} \mathrm{Bz} & =15.87 \mathrm{~T} \\
\mathrm{Gz} & =729 \mathrm{~T}^{2} / \mathrm{m}\end{aligned}$ & $\begin{array}{c}\chi \text { calculated : } 1.69110^{-8} \mathrm{~m}^{3} / \mathrm{kg} \\
\chi \text { in }[3]: 1.684310^{-8} \mathrm{~m}^{3} / \mathrm{kg}\end{array}$ \\
\hline plastic & $\begin{array}{c}\mathrm{Bz}=22.28 \mathrm{~T} \\
\mathrm{Gz}=1923 \mathrm{~T}^{2} / \mathrm{m}\end{array}$ & \multirow{2}{*}{$\begin{array}{c}\text { approximate values since } \\
\text { no shape, size and purity } \\
\text { effects had been taken into } \\
\text { account }\end{array}$} \\
\hline wood & $\begin{array}{c}21 \mathrm{~T}<\mathrm{Bz}<21.5 \mathrm{~T} \\
1648 \mathrm{~T}^{2} / \mathrm{m}<\mathrm{Gz}<1753 \mathrm{~T}^{2} / \mathrm{m}\end{array}$ & \\
\hline water & $\begin{array}{c}26.5 \mathrm{~T}<\mathrm{Bz}<27 \mathrm{~T} \\
2961 \mathrm{~T}^{2} / \mathrm{m}<\mathrm{Gz}<3097 \mathrm{~T}^{2} / \mathrm{m}\end{array}$ & \multirow{3}{*}{$\begin{array}{l}\text { liquids cling to the test } \\
\text { tube before escaping }\end{array}$} \\
\hline ethanol & 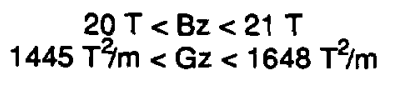 & \\
\hline acetone & $\begin{aligned} 22 \mathrm{~T} & <\mathrm{Bz}<23 \mathrm{~T} \\
1862 \mathrm{~T}^{2} / \mathrm{m} & <\mathrm{Gz}<2086 \mathrm{~T}^{2} / \mathrm{m}\end{aligned}$ & \\
\hline
\end{tabular}

Levitation of liquids occurred for fields higher than those calculated from (1) and the susceptibility data in [3]. This discrepancy is due to wetting and surface tension effects : it was observed that liquids clung to the test tube before leaving it.

\section{Stability of levitation.}

We now extend our discussion to the effects of the variations of the field off axis. It has been shown mathematically that stability of levitation is impossible for paramagnetic particles whereas it can be obtained for diamagnetic particles $[4,5]$. Because of the geometry of the hybrid magnet, it was difficult to confirm that both radial and vertical stability has occurred for diamagnetic substances. To do so, we performed a second experiment at CRTBT in a lower field magnet with a larger bore. In this $8 \mathrm{~T}$ coil, the field and force profiles are similar to those of the hybrid magnet. The exact expressions for the vertical and radial forces are :

and

$$
F_{z}=\left(\chi / \mu_{0}\right)\left(B_{z} \mathrm{~d} B_{z} / \mathrm{d} z+B_{r} \mathrm{~d} B_{r} / \mathrm{d} z\right)
$$

$$
F_{r}=\left(\chi / \mu_{0}\right)\left(B_{z} \mathrm{~d} B_{z} / \mathrm{d} r+B_{r} \mathrm{~d} B_{r} / \mathrm{d} r\right) \text { respectively } .
$$


The vertical field and force are slightly increased off the axis, but conclusions about vertical stability remain the same. The radial field gives only a small contribution to the vertical force. The radial force, whose sign depends on $z$, increases with the distance from the axis of the coil. It can be seen from figure 3 that in the lower region of the vertical stability zone one also has radial stability, whereas for higher regions of the vertical stability zone, the radial force tends to drive the sample from the axis to the inner wall of the magnet. Because of its high diamagnetic susceptibility [6], graphite was chosen for this experiment. Above a certain field, the sample started to levitate and stability was obtained both vertically and radially. As the field was raised further, the sample rose inside the magnet bore and then reached the zone where the radial stability was broken.

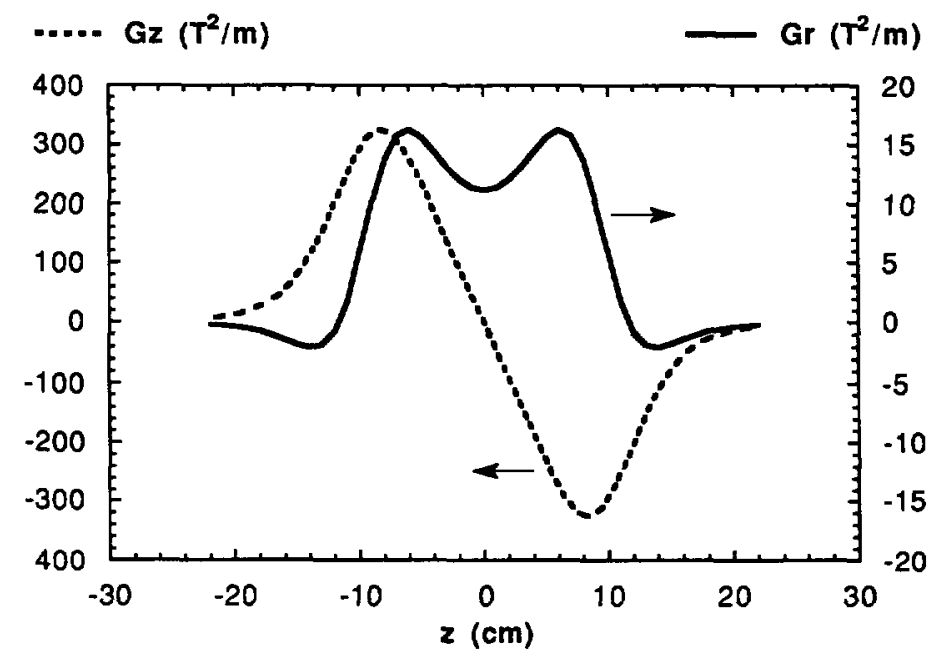

Fig. 3. - Field profiles in the $8 \mathrm{~T}$ magnet. $G_{z}$ and $G_{r}$ are the vertical and radial components of $\operatorname{grad}\left(\mathbf{B}_{\mathrm{a}}^{2} / 2\right)$, calculated on the axis of the coil and $1 \mathrm{~cm}$ from the axis, respectively. Forces acting on a material may be calculated as in figure 1 . One can see that in the region of levitation where vertical stability is achieved $(z>8 \mathrm{~cm}), G$, may either be positive or negative. For $z<12 \mathrm{~cm}$, the force acting on a diamagnetic particle points towards the axis, whereas for $z>12 \mathrm{~cm}$, a diamagnetic particle would tend to be driven away from the axis.

Levitation started for $B_{z} \max =5.25 \mathrm{~T}$ and $B_{z} \mathrm{~d} B_{z} / \mathrm{d} z \max =140 \mathrm{~T}^{2} / \mathrm{m}$. Radial instability was reached at $B_{z} \max =6 \mathrm{~T}$.

Between these limits, a small displacement of the sample makes it oscillate freely around its rest position.

\section{Conclusion.}

We have demonstrated that it is nowadays possible to levitate almost any material by using high static magnetic fields. Beside experimental high performance magnets, commercial superconducting coils are now available which can produce field gradients as high as $2000 \mathrm{~T}^{2} / \mathrm{m}$. This opens the way to numerous new possibilities of contactless material elaboration and the use of magnetic fields is an alternative technique to microgravity experiments in space laboratories. In the case of paramagnetic samples, one has to confine the material in a vertical tube as the radial stability is not achieved in the vertical stability zone. 
However, compensation for gravity is still achieved; moreover, it is well known that a magnetic field can damp convection in conducting liquids [7], which can be helpful for defectless material elaboration. Such experiments on melted alloys are now under study in our laboratory.

\section{Acknowledgements.}

We wish to express our acknowledgements to Pr. G. Aubert and Dr. J. C. Vallier from S.N.C.I., and to Dr. A. Sulpice from C.R.T.B.T. Grenoble, France, for helpful discussions.

\section{References}

[1] LIN I. J., Jones T. B., J. Electrostat. 15 (1984) 53-65.

[2] BRandT E. H., La Recherche 224 (1990) 998-1005.

[3] WEAST R. C., Handbook of chemistry and physics, E-109 (1972-1973).

[4] Jones T. B., J. Appl. Phys. 50 (1979) 5057-5058.

[5] Holmes L. M., J. Appl. Phys. 49 (1978) 3102-3109.

[6] Pinnick H. T., Phys. Rev. 94 (1954) 319-326.

[7] Szekely J., Fluid flow phenomena in metals processing (Academic Press, London, 1979). 